\title{
İlkokul 4. Sınıf Öğrencilerinin Matematik Öğrenmede Sıkıntı Yaşama Düzeyleri ile Yazma Kalitesi Düzeylerinin İncelenmesi
}

\author{
Özlem Doğan Temur \\ Kütahya Dumlupınar Üniversitesi, Eğitim Fakültesi, Temel Eğitim Bölümü, Sınıf Eğitimi ABD, Kütahya \\ ozlem.dtemur@dpu.edu.tr \\ ORCID ID: https://orcid.org/ 0000-0002-1877-0973 \\ Handan Kılıç Şahin \\ Kütahya Dumlupınar Üniversitesi, Eğitim Fakültesi, Temel Eğitim Bölümü, Sınıf Eğitimi ABD, Kütahya \\ handan.kilicsahin@dpu.edu.tr \\ ORCID ID: https://orcid.org/0000-0002-1917-0937
}

Kemal Özdemir

Kütahya Dumlupınar Üniversitesi, Eğitim Fakültesi, Temel Eğitim Bölümü, Sınıf Eğitimi ABD Doktora Öğrencisi, Kütahya ORCID ID: https://orcid.org/0000-0003-2966-2609

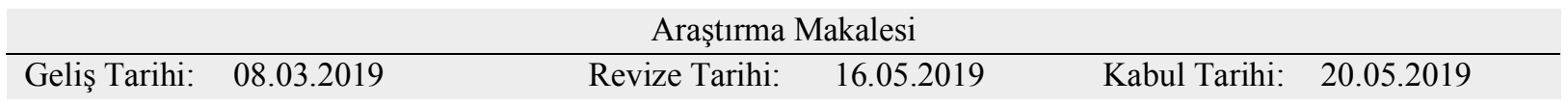

\section{Atıf Bilgisi}

Doğan Temur, Ö., Kılıç Şahin, H. ve Özdemir, K. (2019). İlkokul 4. sınıf öğrencilerinin matematik öğrenmede sıkıntı yaşama düzeyleri ile yazma kalitesi düzeylerinin incelenmesi, Ahi Evran Üniversitesi Sosyal Bilimler Enstitüsü Dergisi, 5(1), 65-80.

\section{ÖZ}

Bu çalışmanın amacı, matematik öğrenmede sıkıntı yaşadığı düşünülen öğrencilerin matematik öğrenmede sıkıntı yaşama düzeyleri ile yazma kalitesi düzeyleri arasındaki ilişkiyi ortaya koymaktır. Araştırma genel tarama modellerinden ilişkisel tarama modelindedir. Araştırmanın çalışma grubu, amaçlı örnekleme yöntemlerinden ölçüt örneklemeye göre belirlenmiş, Kütahya Merkez ile bir ilçesinde bulunan 5 ilkokuldan seçilmiş 4. Sınıf düzeyinde matematik öğrenme sürecinde sıkıntı yaşayan 49 öğrenciden oluşmaktadır. Araştırmanın çalışma grubunu oluşturan öğrenciler belirlenirken öncelikle sınıf öğretmenlerinden matematik dersinde sıkıntı yaşayan öğrencileri belirlemeleri istenmiş, ardından sıkıntı yaşayan öğrencilerin sahip olması gereken özelikler konusunda bilgilendirme yapılmıştır. Bu anlamda çalışma grubunu oluşturan öğrencilerin sahip olması gereken özellikler; öğrenciye herhangi bir öğrenme güçlüğü tanısı konulmaması, öğrencinin öğrenmesi yönünde herhangi belirli bir engelin olmaması, öğrencinin sınıftaki dersleri öğrenme konusunda gerekli çabayı göstermesi olarak belirlenmiştir. . Araştırmanın verileri Matematik Öğrenme Güçlüğü Kontrol Listesi ve Yazma Kalitesi Dereceli Puanlama Anahtarı aracılığıyla toplanmıştır. Her iki araçtan elde edilen puanlar düşük, orta ve yüksek olmak üzere üç kategori altında toplanmıştır. Değişkenler arasındaki ilişkilerin incelenmesinde ki-kare testi kullanılmıştır. Elde edilen bulgulara göre matematik öğrenmede yaşanan sıkıntı düzeyi ile yazma kalitesi düzeyleri arasında bir ilişkinin var olduğu ve bu ilişkinin doğrusal yönde pozitif olduğu bulgusuna ulaşılmıştır. Matematik öğrenmede sıkıntı yaşama düzeyi arttıkça yazma kalitesi düzeyi de düşmektedir.

Anahtar Kelimeler: Matematik öğrenme güçlüğü, yazma kalitesi, ilkokul 4. sınıf öğrencileri.

\section{Investigation of 4th Grade Elementary Students' Levels of Experiencing Difficulty In Mathematics Learning And Their Writing Quality Levels}

\begin{abstract}
The aim of this study is to reveal the relationship between the level of experiencing difficulty in mathematics learning and writing quality levels of the students who are considered to have difficulty in learning mathematics. The research is in correlational survey model from general survey models. The study group of the research was determined by criterion sampling from purposeful sampling methods, was selected from 5 elementary schools located in Kutahya city center and a district, and it included 49 4th grade students who had difficulty in learning mathematics. In determining the students who formed the study group, firstly, primary school teachers were asked to determine the students who had difficulty in the mathematics lesson and then the teachers informed about the characteristics of the students who had difficulties. In this sense, the characteristics that the students of the study group should have; the fact that the student was not diagnosed with any learning disability, and that there was no specific obstacle to the learning of the student was
\end{abstract}


determined as the student making the necessary effort to learn the lessons in the classroom. The research data were collected via Mathematics Learning Difficulty Behavior Checklist and Writing Quality Scoring Rubric. The scores obtained from both tools were categorized in three as low, medium and high. Chi-square test was used to investigate the relationships between variables. According to the findings, it has been reached that there is a relationship between the levels of experiencing difficulty in mathematics learning and writing quality levels and this relationship is positive in linear direction. As the level of experiencing difficulty in mathematics learning increases, the writing quality decreases.

Keywords: Mathematics learning disability, writing quality, elementary school $4^{\text {th }}$ grade students.

\section{Giriş}

Öğrenme güçlüğü, bir alandaki becerinin diğer alanlardaki becerileri etkilemeden belirli bir düzeyde ortaya çıkan yetersizlik olarak tanımlanabilir. Öğrenme güçlüğü yaşayan öğrenciler aynı zamanda sosyal ve duygusal zorluklar da yaşamaktadırlar (Terry, 2013). Öğrenme güçlüğü yaşayan öğrencilerde dil, alg1, dikkat, bellek, hatırlama, kodlama ve bellekten geri çağırmada eksiklikler ile detayları daha az fark etme gibi özelikler gözlemlenebilir. Öğrenme güçlüğü olan öğrenciler sözel, görsel-uzamsal becerilerde de yaşıtlarına oranla daha düşük performans sergilemektedirler. Öğrenme güçlüğü olan öğrencilerin matematiğin birçok alanında sorun yaşadıklarına yönelik tespitler bulunmaktadır (Bender, 2016). Toptaş ve Gözel'e (2018) göre birçok önyargıyı içinde barındıran matematik dersine yönelik bireylerin kaygı ve olumsuz tutuma sahip olduğu, yine matematik dersinin bireylerin en çok zorlandığı ders olarak bilindiği söylenebilir. Öğrenme güçlüğü olmayan öğrencilerde de normal zekâ, yeterli eğitim ve öğretim faaliyetlerine rağmen matematiğin çeşitli alanlarında öğrenmede sıkıntılar ortaya çıkabilmektedir (Mutlu ve Akgün, 2017). Bazı öğrenciler sadece okuma ya da matematik alanında, bazıları ise her iki alanda da yetersizlikler sergileyebilmektedirler (Robinson, Menchetti ve Torgesen, 2002). Matematik öğrenme güçlüğünün nadiren tek başına görülmesi matematiksel zorluklarla ilişkili bilişsel süreçlerin tanımlanmasını zorlaştırabilmektedir. Her ne kadar matematik öğrenme güçlüğü birçok diğer engelle ilişkili olsa da, matematik öğrenme güçlüğü yaşayan öğrencilere siklıkla dikkat eksikliği hiperaktif bozukluğu (DEHB) veya okuma yetersizliği tanısı konur. Matematik öğrenme güçlüğünün diğer güçlükler veya bozukluklara eşlik etmesi, matematik becerilerinde ve bilişsel bozukluklarda farklı türlerde zorlukların olduğunu gösterebilmektedir. Örneğin, Geary (1993) ile Jordan ve Hanich (2000) yalnızca matematik öğrenme güçlüğü yaşayan öğrencilerin, hem matematik öğrenme güçlüğü yaşayan hem de okuma yetersizliği olan öğrencilerden hikâye problemleri ve yazılı hesaplamalar konusunda daha iyi performans gösterdiğini bulmuşlardır. Bununla birlikte üçüncü ve dördüncü sınıflardan çocukların bulunduğu bir örneklemde Andersson (2008), yalnızca matematik öğrenme güçlüğü yaşayan öğrenciler ile hem matematik öğrenme güçlüğü yaşayan hem de okuma yetersizliği olan öğrencilerden oluşan öğrenci grubunun matematiğin tüm alanlarında eşit derecede zayıflık gösterdiğini gözlemlemiştir (Watson ve Gable, 2012).

Ülkemizde Matematik dersi öğretim programının çocukların gelişim düzeylerine göre geliştirilmiş standart bir program olarak uygulandığını söyleyebiliriz. Matematik dersi öğretim programında problem çözme, sınıflama ve ilişki kurma gibi beceriler yer almaktadır (Mili Eğitim Bakanlığı [MEB], 2018). Bazı öğrenciler bu becerileri edinmede sıkıntılar yaşayabilmektedirler. Matematik dersi öğretim programında kazanımlar sayılar ve işlemler öğrenme alanı, doğal sayılarla toplama ve çıkarma alt öğrenme alanları ile birinci sınıfta toplama ve çıkarma işlemi olmak üzere iki temel işlemle başlamaktadır (MEB, 2018). Matematikte sıkıntı yaşayan öğrenciler sıkıntının derecesine göre temel matematik becerileri edinmede zorluklar yaşamaktadırlar (Sullivan, 2005). Matematikte öğrenme güçlüğü olan öğrenciler matematiğin tüm alanlarında sıkıntı yaşayabildiği gibi matematiğin tüm alanlarını kapsamayan durumlarda da sıkıntı yaşayabilirler. Örneğin öğrenciler dört işlemi yapabilmekte fakat problem çözmede bu becerileri kullanmada zorlanabilmektedirler. Okulun ilk yıllarında öğrenme güçlüğü çeken öğrenciler somut nesnelerle yaptırılan çalışmalarda herhangi bir güçlük çekmemekle birlikte işlemler soyut hale geldikçe sıkıntılar daha belirgin olarak kendini göstermektedir. Örneğin bir basamaklı sayıları toplarken parmaklarını kullanan bir öğrenci iki basamaklı sayıları toplarken bu yöntem işe yaramadığı için sıkıntı yaşamaktadır (Bender, 2016). Öğrencilerin belirli deneyimlerle ve ileri sınıf düzeylerinde belirli bir hıza ulaşması beklenmektedir. Örneğin ilkokul 3. Sınıfta öğrenciler bir basamaklı sayılarla yapılan toplama ve çıkarma işlemlerinde 
sonucu doğrudan söylemektedir. Bu, öğrencinin işlem becerisinde otomatikleştiğini gösterir (Sousa, 2014). Çok basamaklı dört işlemlerde öğrencilerin kullandıkları stratejiler öğrencilerin matematikte sıkıntı yaşayıp yaşamadıkları ile ilgili ipuçlarını göstermektedir. Çok basamaklı işlemlerde öğrencilerden basamak değerinin algılanması, işlem aşamalarını göstermesi ve işlemi yeterli düzeyde tamamlaması beklemektedir. Matematikte sıkıntı yaşayan öğrencilerde basamak değerinin algılanması ve işlem aşamalarında problemler ortaya çıkmaktadır (Bender, 2016). Öğrenciler görsel uzamsal algıdaki problemler nedeniyle veri işleme ve geometri alanlarında zorlanmaktadırlar (Geary, Hoard, Byrd-Craven ve Desoto, 2004). Öğretmenler, öğrencilerde görülen işlem hatalarını fark edebilmekte ancak öğretim aşamalarında öğrencilerin yaptıkları hataları göz önünde tutmamaktadırlar (Riccomini, 2005). Matematik öğrenmede sıkıntı yaşayan öğrencilerin işlem hataları işlemi nasıl yaptıklarını açıklama sürecinde ortaya çıkmaktadır. Öğrencinin herhangi bir işlemin çözümünü nasıl yaptığını ifade edebilme düzeyi ile işlemi çözerken kullandığı strateji öğrencinin matematik öğrenmede yaşadığ1 sıkıntıya dair ipuçları verebilir (Bender, 2016).

Matematik öğrenmede sıkıntı yaşayan çocukların genel olarak sahip olduğu özellikler şu şekildedir: Sayıları öğrenmede gecikme ya da zayıflık, sayılar arası ilişkilerde ve örüntülerde yetersizlikler, sayının rakamlarının yerini karıştırma, problem sözel olarak anlatıldığında çözebilme fakat kendisi okuduğunda çözememe, dört işlem becerilerinde yanlış basamaktan başlama, işlemlerdeki aşamaları unutma, üst sınıf düzeylerinde bir ya da iki basamaklı sayılarla yapılan işlemlerde otomatik hale gelememe, zaman kavramını öğrenememe, hesaplamada basit stratejiler ve parmakları kullanma, somut nesnelere ihtiyaç duyma, matematik dilini anlamada zorlanma, temel matematik becerilerinde zayıflı (Baroody ve Kaufman,1993; Emerson ve Babtie, 2010; Garnett, 1992; Mutlu, 2016; Kalaç, 2017). Öğrenme güçlüğü tanısı konulmamış birçok çocuk matematik alanında özel öğretim stratejilerine ihtiyaç duyabilmektedir. Öğrenme güçlüğü tanılama sürecinde bir $\tan 1$ konulmadığı halde matematik öğrenmede sıkıntı yaşayan öğrenciler olduğu göz ard1 edilebilmektedir (Bender, 2016). Matematik öğrenmede sıkıntı yaşadığ 1 düşünülen öğrencilerdeki problemin kaynağı, öğrencinin zorlandığ zihinsel aktivitelerdeki yetersizlikler olarak görülmektedir. Bunun yanı sıra öğrencilerin uzun süreli bellek, kısa süreli bellek, işleyen bellek bakımından da sıkıntılar yaşadığı düşünülmektedir. İşleyen bellek yönünden sıkıntı yaşayan öğrenci sayılar arası ilişkilerde zorlanmaktadır. Uzun süreli bellek problemi olan öğrenciler hatırlamada zorluklar yaşamaktadır. Kısa süreli bellekte sıkıntı yaşayan öğrenciler ise cevaba ulaşmadan önce soruyu hatırlamada zorlanmaktadırlar (Emerson ve Babtie, 2010; Geary, Hoard, Byrd-Craven ve Desoto, 2004; Karagiannakis ve Baccaglini-Frank, 2014). Baz1 araştırmacilar (örneğin Lee ve Kang, 2002; Mabbott ve Bisanz, 2008; Passolunghive Siegel, 2001) bilişsel süreçler (örneğin, işleyen bellek ve yürütücü işlevler) ile matematikte öğrenci başarısı arasında pozitif yönde bir ilişki olduğunu bulmuşlardır. $\mathrm{Bu}$ bulgu da matematik öğrenme zorluğu yaşayan ögrencilerin performansını vurgulamaktadır (Watson ve Gable, 2012) . Presseley ve Harris'e (2006) göre işleyen bellek, uzun süreli bellekteki bilgilerin etkin hale geldikten sonra aktarıldığı, aktarılan bilgiler üzerine düşünülürek değişiklikler yapıldığı sınırlı bir kapasiteye sahip bellek türüdür. Öğrenme ve dil becerilerindeki bozuklulukların kaynağı işleyen bellek kapasitesinin düşüklüğü ile ilişkilidir (Akt: Ülper, 2008) Dil becerileri içerisinde en zor kazanılan beceri olan yazma Vanderburg'a (2005) göre başarılması güç bir beceridir çünkü yazma sürecinde bellek, dikkat, problem çözme, motivasyon gibi çok sayıda bilişsel beceriler kullanılmaktadır.

Teorik olarak eğitimcilerin çoğu bütün öğretmenlerin okuma yazma öğretmeni olduğu konusunda görüş birliğindedir. Artan sayıdaki araştırmalar, okuma ve yazma becerilerinin tüm öğrenme alanlarında bütünü oluşturan önemli unsurlar olduğunu ve öğrenmede disiplinler arası yaklaşımın faydalı olduğunu ileri sürmektedirler. Bununla birlikte matematiğin bazı konu alanları okuma ve yazma ile daha az ilişkili olduğu için çok sayıda eğitimci bu teoriyi uygulamaya geçirmekte zorlanmaktadır (Vukovich, 1985).

Yazmaya bir problem çözme süreci olarak bakıldığında özellikle de kelime problemi çözümlerinde öğrenciler benzer bilişsel süreçleri kullanırlar (Williamson ve Mcandrew, 1987). Dolayısıyla matematik alanında sıkıntı yaşayan öğrencileri belirlemede matematik konu alanlarının tümünün taranmasının yanı sıra matematik konu alanı dışında okuma, yazma gibi alanlarda sınıf 
düzeyinin altında performans gösterilmesinin matematikte yaşanan sıkıntılarla ilişkili olabileceği unutulmamalıdır. İlkokul düzeyinde özel öğrenme güçlüğü yaygınlı̆̆ 1 üzerine yapılan çalışmalarda Görker, Bozatl1, Korkmazlar vd. (2017) matematik öğrenme güçlüğü oranını \%6,5; Gross-Tsur, Manor, ve Shalev (1996) matematikte sıkıntı yaşayanların oranını \%3-6; Shalev ve Gross-Tsur (2001) ise okulda bu oranları \%5-6 olarak belirlemişlerdir. Bu oranlar küçümsenemeyecek rakamları ortaya koymaktadır. Bu nedenle matematik öğrenmede sıkıntı yaşayan öğrencilerin bu sıkıntılarını göz ardı etmeyecek şekilde düzenlemeler yapılmalıdır (Petra Scherer, 2017).

Yazma çok sayıda yüksek düzeyde bilişsel ve üst bilişsel becerilerin koordinasyonunu içeren karmaşık bir süreçtir (Olinghouse ve Wilson, 2013). Yazma insanoğlunun yaşam boyunca başarmaya çalıştığı en kompleks bilişsel etkinliklerden biridir ve farklı düzeylerdeki gösterimlerde işleyen çok sayıda bilişsel bileşeni kapsamaktadır (Hayes, 1996; Akt: Olive, 2003). Yazma akademik yaşamda ve iş yaşamındaki başarılarda kritik önem taşımaktadır. İyi bir yazı yazmak için öğrencilerin beklentilerini karşılayabilecek etkili öğretimi sağlamak önemli bir amaç olmalıdır. Bu amaç yazının hangi yönlerinin yazma kalitesi açısından önemli olduğuna dair anlayışın gelişmesini gerekli kılmaktadır (Crossley ve McNamara, 2016). Olinghouse ve Wilson'a (2013) göre bilişsel yazma modelleri yazarın kaliteli metin üretimi için ihtiyaç duyduğu bilişsel ve dilbilimsel kaynaklara vurgu yapmaktadır. Bir metnin olabildiğince iyi hale getirilmesi için yazarların yazma sürecinde hem bilgi hem de yazma becerilerini hatırlayıp dengeleyebilmeleri için yeterli bilişsel kapasiteye sahip olmaları gerekmektedir (Lindgren, 2005). Dolayısıyla bilişsel bir yönü de olan yazma becerisi, matematik ile benzer bir şekilde bellek, dikkat, problem çözme gibi çok sayıda bilişsel değişkeni kapsamakta; bu değişkenler de iki alanının birbiriyle ilişkili olduğunu göstermektedir. Buradan yola çıkarak yazma becerisinin önemli bir göstergesi olarak yazma kalitesi araştırmanın bir değişkeni olarak ele alınmıştır.

\section{Araştırmanın Amacı}

Eğitimde kullanılan yazma kalitesi ölçümleri fikir-içerik gelişimi, planlama, cümle akıcılığı, kelime seçimi, üslup ve kurallar gibi ölçütlerde toplanmaktadır (White ve Bruning, 2005). Yazma kalitesi yazılı ürünlerin okunaklığı açısından değerlendirilebilir (Jasper, Gordijn, Häußler ve Hermsdörfer, 2011). Matematik dersinin içerisinde de yazma ve iletişimin önemli olduğunu söyleyebiliriz. Öğrenciler yazarken ve iletişim kurarken anladıkların birleştirebilir ve genişletebilirler. Öğretmenler, çocuklar arasında farklılıklar olduğunu bilmeli ve yazma çalışmalarında da çocuklar arasında farklılıklar olacağını unutmamalıdırlar (Burns, 2005). Yazmak; duygularını, matematik hakkındaki inançlarını ve bilgilerini açıklamaları için çocukları cesaretlendirebilir. Negatif duygularla mücadele etmelerine, okul matematiği içerisinde yer alan becerileri edinmelerine yardımcı olabilir. Yazma öğretmen öğrenci ilişkisini ve sınıf atmosferini etkileyebilir, öğretmen ve öğrenciler bu yolla daha özgür iletişim kurabilirler (Borasi ve Rose, 1989). Yazma etkinlikleri öğretmen ve öğrenci arasında güçlü bir iletişim sağlar (Miller, 1991).

Sınıf ortamında öğrenciler okuma, matematik ya da her ikisinde başarısızlık yaşıyorsa ve bu başarısızlık öğretmen ve veliler tarafinda hissediliyor, öğrenciler için yardıma ihtiyaç duyuluyorsa çocukta öğrenme güçlüğünün varlığından bahsedilebilir (Wilmshurt ve Brue, 2010). Buradan hareketle çalışmanın amacı herhangi bir öğrenme güçlüğü tanısı konulmamış fakat sınıf içinde matematik derslerinde akademik anlamda yeterli düzeyde başarı gösteremeyen öğrencilerin matematik öğrenmede yaşadığı sıkıntı düzeyleri ile yazma kalitesi düzeyleri arasında ilişki olup olmadığını belirlemektir.

\section{Araștırmanın Önemi}

Öğrencilerin ifade becerilerinin gelişimi; erken çocukluk döneminde bulunduğu ortamda matematik ile ilgili materyallerin bulunması ve matematikle ilgili ifadelerin sıklıkla kullanılması ile birlikte çocuklarda kelime hazinesinin oluşumu ve çocukların anaokulunda okuma-yazma etkinliklerinin sonuçları ile ilişkili olduğu ifade edilebilir (Napoli ve Purpura, 2017). Çocuklar için okulda hazırlanan sınıf içi etkinlikler ilkokulda doğal bir yapıda olmayabilir. Çünkü okullarda dil ve matematik alanlarının her biri için materyaller ve etkinlikler hazırlanır ve bu iki konu alanı birbirinden 
farklı olarak görülebilir. Çocukların dünyasında örüntüler, problem çözme ve iletişim önemli bir yere sahiptir. Öğretmenler bu iki konu alanını birbirine entegre edebilmeli, kaliteli ve önemli uygulamalar ortaya koyabilmelidir (Moyer, 2000). Yazma matematik öğrencilerine çok farklı yollarla yardım edebilir. Yazması gereken öğrenciler yazmadan önce önemli düşünceler geliştirebilir ve düşüncelerini organize edebilirler böylece kavram çalışmaları zihinlerinde daha iyi yerleşebilir (Johnson, 1983). Yazma ve yazmanın kalitesi öğrencilerin kendilerini daha etkili ifade edebilmeleri için önemli bir araçtır. Matematik becerileri öğrencilerin kendilerini ifade etme yollarıyla daha iyi değerlendirilip geliştirilmesi için öğrencilere daha etkili yardımda bulunma firsatları sunabilir. Bu nedenle matematik ve yazma kalitesi arasındaki ilişkinin varlığı hakkında düşünmek, araştırmalar yapmak ve bu ilişkiye dair bilimsel bilgiye ulaşmak bu çalışmanın önemini ortaya çıkarmaktadır.

\section{Yöntem}

Araştırma genel tarama modellerinden ilişkisel tarama modelindedir. İlişkisel tarama modelleri iki veya daha çok sayıdaki değişken arasında birlikte değişim varlığını ve/veya derecesini belirlemeyi amaçlamaktadır (Karasar, 2006, s.81). Bu çalışmada öğrencilerin matematik öğrenmede sıkıntı yaşama düzeyleri ile yazma kalitesi düzeyleri arasında ilişki olup olmadığı ve bu ilişkinin düzeyi araştırılmıştır.

\section{Çalışma Grubu}

Araştırmanın çalışma grubu, amaçlı örnekleme yöntemlerinden ölçüt örneklemeye göre belirlenmiştir. Çalışma grubunu Kütahya Merkez ile bir ilçeden seçilen toplam 5 ilkokulda öğrenim gören 49 öğrenci oluşturmaktadır. Araştırmaya dâhil edilen okullardan araştırma için gerekli izinler alınmıştır. Öğrenciler belirlenirken ilgili sınıfi okutan öğretmene araştırma konusuna, davranış kontrol listesinin yapısına ve listeyi nasıl dolduracağına yönelik yüz yüze detaylı bilgilendirme yapılmıştır. Ayrıca öğrencilerin yazma kalitesi düzeylerinin belirlenmesi amacıyla ilgili öğretmen tarafından öğrenciden kendisinin tasarlayacağı bir hikâye yazması istenmiştir.

Araştırmanın çalışma grubunu oluşturan öğrenciler belirlenirken öncelikle sınıf öğretmenlerinden matematik dersinde zorlanan öğrencileri belirlemeleri istenmiş, ardından zorlanan ve sıkıntı yaşayan öğrencilerin sahip olması gereken özelikler konusunda bilgilendirme yapılmıştır. $\mathrm{Bu}$ anlamda çalışma grubunu oluşturan öğrencilerin sahip olması gereken özellikler; öğrenciye herhangi bir öğrenme güçlüğü tanısı konulmaması, öğrencinin öğrenmesi yönünde herhangi belirli bir engelin olmaması, öğrencinin sınıftaki dersleri öğrenme konusunda gerekli çabayı göstermesi olarak belirlenmiştir. Öğretmenlerden belirlenen bu özellikler bağlamında öğrenci seçimi yapmaları istenmiştir. Seçilen öğrenciler arasından bu özellikleri gösterenler araştırmanın çalışma grubunu oluşturmuştur. Öğretmenler çalışma grubunu oluşturan her bir öğrenci için ayrı ayrı Matematik Öğrenme Güçlüğü Davranış Kontrol Listesi doldurmuştur ve yine her bir öğrenciye hikâye edici bir metin yazdırmıştır. Buna göre çalışma grubu öğrenim gördüğü sınıfta matematik öğrenme sürecinde sıkıntı yaşayan 49 öğrenciden oluşmaktadır.

\section{Verilerin Toplanması}

Araştırmanın verileri araştırmacılar tarafından hazırlanan Matematik Öğrenme Güçlüğü Davranış Kontrol Listesi ve Yazma Kalitesi Dereceli Puanlama Anahtarı aracılığıyla toplanmıştır. Matematik öğrenme güçlüğü davranış kontrol listesi, ilkokul 4. sınıfta öğretim yapan ve sinıfında matematik öğrenmede sıkıntı yaşadığı düşünülen bir ya da daha fazla öğrenci bulunan 24 sınıf öğretmeni tarafından gönüllülük esasına dayalı olarak doldurulmuştur. 24 sınıf öğretmeni tarafından belirlenen matematik öğrenmede sıkıntı yaşadığı düşünülen toplam 49 öğrenciden aynı zamanda kendilerinin tasarlayacağı bir hikâyeyi uygun ortamlarda yazmaları istenmiştir. Elde edilen 49 metin "Yazma Kalitesi Dereceli Puanlama Anahtarı" aracılığıyla değerlendirilmiş ve yazma kalitesine yönelik veriler toplanmışırır. 


\section{Veri Toplama Araçları}

\section{Matematik Ö̆̆renme Güçlüğ̈̈ Davranış Kontrol Listesi}

Öğrenme güçlüğünün belirlenmesinde ve gerekli öğretimsel düzenlemelerin yapılmasında gözlemler önemli yer tutar. Gözlemler yolu ile öğrencinin akademik ve davranış özellikleri ile ilgili bir kanıya varılır. Örneğin öğrencinin derse katılımı, ders sırasındaki davranışları gözlemler yoluyla kayıt tutularak belirlenebilir (Özmen, 2017). Matematik öğrenme güçlüğü davranış kontrol listesinde öğrencilere yönelik öğrenme güçlüğü ifadelerini içeren 32 adet madde yer almaktadır. Bu maddeler, uluslararası ve ulusal literatür taraması sonucunda matematik öğrenme sürecinde yaşanan sıkıntıları tanımlayan ifadeler arasından seçilmiştir (Baroody ve Kaufman 1993; Bender, 2016; Garnett, 1992; Jordan ve Hanich, 2015; Gross-Tsur, Manor ve Shalev, 1996; Görker ve diğerleri , 2017; Karagiannakis ve Baccaglini-Frank, 2014; Mutlu, 2016; Mutlu ve Akgün, 2017; Petra Scherer, 2017; Robinson, Menchetti ve Torgesen, 2002; Shalev ve Gross-Tsur, 2001; Terry , 2013; Wilmshurt ve Brue, 2010) . Her ne kadar Matematik Öğrenme Güçlüğü Davranış Kontrol Listesi denilmiş olsa da öğrencilerin güçlük tanısı almamaları nedeniyle 'güçlük' yerine ‘sıkıntı' kelimesini kullanmaya bu çalışmada özellikle dikkat edilmiştir. Öğretmenlerin seçtiği öğrencilerin yalnızca bir tanesinin düşük düzey diğerleri ise orta ve ileri düzey sıkıntı yaşadıkları dikkati çekmektedir. Bu ise öğrencilerin güçlük tanımına uyan birçok özelliği taşıdıklarını düşündürebilmektedir.

Kontrol listesi matematik öğrenme güçlüğünün literatürde karşılığ1 olan öğrenci davranış betimlemelerini içermektedir. Kontrol listesi, listedeki her bir maddeden öğrenciyle ilgili olanlar çarp1 işareti ile $(\mathrm{X})$ işaretlenebilecek bir yapıda hazırlanmıştır. Hazırlanan kontrol listesi iki alan uzmanı ve bir sınıf öğretmeni tarafindan incelenmiştir. Bunun sonucunda aynı anlamı içerdiği düşünülen maddeler birleştirilerek tek madde halinde ifade edilmiştir, bazı maddelerde dil ve anlatım yönünden düzeltmeler yapılmıştır. Formdan madde çıkarılmamıştır. Formda iki sütun yer almaktadır. İlk sütun davranış ifadelerinden oluşmaktadır, ikinci sütun ise öğrencide beklenen davranış mevcut ise işaret konulması ya da boş bırakılmasına yöneliktir. Kontrol listesinde ayrıca anlaşılamayacağı düşüncesiyle bazı maddeler örnekler verilerek açıklanmaya çalışılmıştır. Örneğin "tekrarlayan hatalar yapar." maddesine örnek olarak "yapılan uyarılara rağmen aynı hatayı tekrarlamaya devam etmesi..." gibi açıklamalar getirilmiştir.

Kontrol listesi, sınıflarında matematik öğrenme sürecinde sıkıntı yaşayan öğrencileri için sınıf öğretmenleri tarafindan doldurulmuştur. Matematik öğrenme güçlügü davranış kontrol listesinde bir bölüm örnek olarak aşağıda verilmiştir.

\begin{tabular}{|l|l|}
\hline Matematik Öğrenme Güçlüğü İfadesi & $X$ \\
\hline Sayıları ögrenirken zorlanır. & \\
\hline İslem yaparken strateji kullanmak yerine parmaklarını kullanır. & \\
\hline $\begin{array}{l}\text { Sadece matematik dersinde değil diğer derslerde de zorluk } \\
\text { yaşamaktadır. }\end{array}$ & \\
\hline $\begin{array}{l}\text { Akranlarıyla kıyaslandığında matematik öğrenmede seviye farklılığ } 1 \\
\text { vardır. }\end{array}$ & \\
\hline Yaptığı işlemleri ve çözdüğü problemleri açıklamada zorlanır. & \\
\hline Sorulan soruya cevap verirken çekingen davranır ya da acele eder. & \\
\hline Hareketli bir yapısı vardır. & \\
\hline $\begin{array}{l}\text { Tekrarlayan hatalar yapar. (Örneğin, yapılan uyarılara rağmen aynı } \\
\text { hatayı tekrarlamaya devam etmesi) }\end{array}$ & \\
\hline
\end{tabular}

\section{Yazma Kalitesi Dereceli Puanlama Anahtart}

Sınıf öğretmenlerinin belirlediği matematik öğrenme sürecinde zorluk yaşayan öğrencilerin yazdığı hikâye edici metinler "Yazma Kalitesi Dereceli Puanlama Anahtarı" aracılığıyla değerlendirilmiştir. Dereceli puanlama anahtarları öznel değerlendirmelerin belirli bir düzeyde 
nesnellik ortaya çıkarılması amacıyla kullanılır. Dereceli puanlama anahtarları ürünün bütünü ya da ürünü parçalara ayırarak her bir bölüm için ayrı puanlama yapılarak ölçme yapılmaktadır.

Çağdaş ölçme değerlendirme yaklaşımlarına göre öğrencinin ürün veya davranışlarını yanlış veya doğru gibi kesin çizgilerle ayırmaktan ziyade öğrencinin bir davranışı veya ürününü sergilerken onun hangi seviyede olduğunun belirlenmesinin daha anlamlı olduğu düşünülmektedir. Öğrenci seviyeleri ise rubrikler olarak da tanımlanan dereceli puanlama anahtarları yoluyla tespit edilmektedir (Çepni, 2012). Araştırmada kullanılan dereceli puanlama anahtarı analitik olarak hazırlanmıştır. Analitik derecelendirme ölçeğinde puanlama işlemi davranışların gerçekleştirilme derecelerine göre yapılmaktadır (Ülper, 2008, s. 122).

Analitik puanlama anahtarları; ürünün veya sürecin bölümlere ayrıldığı, her becerinin veya kriterin bağımsız olarak değerlendirildiği ve son olarak da değerlendirme sonunda elde edilen puanların toplanması yoluyla toplam puana ulaşıldığı dereceli puanlama anahtarı türüdür. Puanlar hem toplama ulaşmak için hem de kriterlerin veya kategorilerin ortalama puanını belirlemek için toplanabilir. Analitik puanlama anahtarları uygulayıcılara, öğrencinin güçlü ve zayıf yönleri hakkında bütüncül puanlama anahtarlarına göre daha ayrıntılı, özel veya uygulamaya dönük veriler sunduğu için ölçme-değerlendirme sürecine daha çok katkı sağlamaktadır (Çepni, 2012).

Analitik dereceli puanlama anahtarının geliştirilebilmesi için uygun bir yazılı metin üretimine yönelik öğrencilerin sahip olması gereken performans göstergelerinin belirlenmesi ve performans gösterge derecelerinin ağırlıklarına göre sınıflandırılması gerekmektedir.

Analitik puanlama anahtarlarını oluştururken izlenmesi gereken adımlar şunlardır:

1. Değerlendirilecek kriterlere karar verilir: Kriterler isimlendirilir ve kriterlerin kısa olmasına dikkat edilir. Ölçeğin sol tarafina kriterler, sağ tarafına ise kriterlerin düzeyleri listelenir.

2. Performans düzeylerinin sayısı belirlenir: Performans düzeyleri amaca göre belirlenir. Ancak 4-5 düzeyden daha fazla düzey belirmek, düzeyler arasındaki ayırımın yapılmasını zorlaştıracağı için çok fazla tercih edilmez.

3. En yüksek düzeyden başlayarak beklentiler belirlenir: her düzey için beklenen açıklamalar ve tanımlamalar yapılır. Öncelikle en yüksek düzey açıklanır daha sonra diğer her bir düzey açıklanır (Çepni, 2012).

$\mathrm{Bu}$ bağlamda Dereceli puanlama anahtarı oluşturulurken ilk adımda uluslararası ve ulusal literatür taraması sonucunda hikâye edici bir metnin sahip olması tür ve yapı özellikleri ile yazılı bir metin olarak hikâye edici metnin sahip olması gereken ölçütler belirlenmiştir. Hikâye edici metnin yazma kalitesi açısından değerlendirmeye yönelik olarak hazırlanan dereceli puanlama anahtarı "Başlık, Giriş, Gelişme, Sonuç, Yazım Kuraları-Noktalama, Paragraf, Ana Fikir, Mantıksal Bütünlük, Tutarlılık ve Sayfa Düzeni” olmak üzere on temel ölçütü kapsamaktadır.

İkinci adımda ise belirlenen temel ölçütler bağlamında öğrencilerin bu ölçütleri sergileme düzeyleri tanımlanmış ve ağırlıklarına göre sınıflandırılmıştır. Öğrencilerin ölçütleri sergileme düzeyleri ağırlıklarına göre 1-3 puan arasında sınıflandırılmıştır. Buna göre DPA'dan alınabilecek en düşük puan 10 iken en yüksek puan ise 30'dur. Puanlama anahtarında 3 düzey belirlenmesinin nedeni çalışma grubunun 4. sınıf olması ve çalışma grubunun hikâye edici metin için yazma kalitesi performans gösterge düzeylerinin ayrımının daha net olacağının düşünülmesidir.

Ortaya çıkarılan dereceli puanlama anahtarı 3 uzman ve 2 Alan uzmanı tarafindan değerlendirilmiştir. Bu değerlendirme sonucunda dereceli puanlama anahtarına son şekli verilmiştir.

\section{Verilerin Analizi}

Kontrol listesinde yer alan ifadelere yönelik öğretmen görüşleri analiz edilirken öncelikle yüzde (\%) ve frekans (f) değerleri hesaplanmıştır. Bu yüzde ve frekans değerlerinden hareketle kontrol listesinde bulunan ve en çok tekrar sayısına sahip olan ifadeden en az tekrar sayısına sahip ifadelere doğru bir sıralama yapılmıştır. Tekrar sayısına göre yapılan sıralamadan yararlanarak matematik 
öğrenme güçlüğüne yönelik bir sınıflama elde edilmiştir. Bu sınıflamaya göre 33 -23 ileri düzey, 2212 orta düzey, 1-11 düşük düzey sıkıntı olarak üç kategoride değerlendirilmiştir.

Kontrol listesinin geçerlilik çalışması için uzman görüşüne başvurulmuştur. Alanda uzman iki akademisyen ve iki öğretmen tarafından kontrol listesi incelenmiş ve madde ifadeleri üzerinde çalışılmıştır. Tekrarlayan maddeler tek madde olarak ifade edilirken bazı maddelere açıklayıcı ifadeler eklenerek kontrol listesine son hali verilmiştir.

Yazma Kalitesi Dereceli Puanlama Anahtarı ile elde edilen verilerde öğrenciler düşük, orta ve yüksek düzey olmak üzere üç kategoride toplanmıştır. 0-10 ileri düzey güçlük, 11- 20 orta düzey güçlük, 21-30 düşük düzey güçlük olarak üç kategoride değerlendirilmiştir. Değişkenler arasındaki ilişkilerin incelenmesinde ki-kare testi kullanılmıştır. Parametrik olmayan bir istatistik olarak ki-kare testi iki sınıflamalı değişkenin düzeylerine göre oluşan gözeneklerde gözlenen değerlerle, beklenen değerlerin birbirlerinden anlamlı bir şekilde farklılık gösterip göstermediğini test etmek amacıyla kullanır. İki değer arasındaki fark arttıkça değişkenler arasındaki ilişkinin anlamlı çıkma olasılığı artar (Büyüköztürk, Çokluk ve Köklü, 2016).

Matematik Öğrenme Güçlüğü Davranış Kontrol Listesi ve Yazma Kalitesi Dereceli Puanlama Anahtarı'ndan ortaya çıkan frekans değerlere göre Tablo 1 incelendiğinde değişkenlere ait kategori ve sütunlar görülmektedir.

Tablo 1.

Matematik Öğrenmede Sıkıntı Yaşayan Öğrenci ve Yazma Kalitesi Düzeylerine Göre Ögrenci Sayıları

\begin{tabular}{lccclccc}
\multicolumn{3}{c}{ Mat Öğr. Sk. Yaşama Kategorileri } & \multicolumn{3}{c}{ Yazma Kalitesi Düzeyleri Kategorileri } \\
Kategori & $\mathrm{n}$ & Yüzde & Toplam Yüzde & Kategori & $\mathrm{n}$ & Yüzde & Toplam Yüzde \\
Düsük & 1 & 2,0 & 2,0 & Düsük & 7 & 14,3 & 14,3 \\
Orta & 25 & 51,0 & 53,1 & Orta & 32 & 65,3 & 79,6 \\
İleri & 23 & 46,9 & 100,0 & İleri & 10 & 20,4 & 100,0 \\
Toplam & 49 & 100,0 & & Toplam & 49 & 100,0 & 100,0 \\
\hline
\end{tabular}

Tablo 1 incelendiğinde matematik öğrenmede sıkıntı yaşayan düşük düzey 1 , orta düzey 25 , ileri düzey ise 23 öğrenci; yazma kalitesine göre ise düşük düzey 7, orta düzey 32 , ileri düzey 10 öğrenci olduğu görülmektedir.

\section{Bulgular}

Bu çalışmada öğrencilerin yaşadığı matematik öğrenme sıkıntısı ile yazma kaliteleri düzeyleri arasında bir ilişkinin olup olmadığı incelenmiştir. Matematik öğrenmede sıkıntı yaşama ile öğrencilerin yazma kalitesi; düşük, orta ve yüksek düzey olmak üzere üçer kategori olarak düşünülmüştür. Tablo 1 incelendiğinde Matematik öğrenmede 1 öğrenci orta düzeyde sıkıntı yaşamakta, 25 öğrenci orta düzey sıkıntı yaşamakta, 23 öğrenci ise yüksek düzeyde sıkıntı yaşamaktadır. Yazma kalitesi açısından 7 öğrenci düşük düzeyde, 32 öğrenci orta düzeyde, 10 öğrenci ise yüksek düzeyde yer almaktadır. Çalışmada elde edilen bulgulara göre matematik öğrenmede sıkıntı yaşadığı düşünülen öğrencilerin aynı zamanda yazma kalitesi düzeylerinin de düşük olduğu, ayrıca matematik öğrenmede sıkıntı yaşama düzeyi ile yazma kalitesi düzeyi arasında orta düzeyde doğrusal bir ilişkinin varlığı belirlenmiştir. Katılımcıların matematik öğrenmede sıkıntı yaşama ile yazma kalitesi düzeylerinin kategorilere göre dağılımı; Matematik öğrenmede sıkıntı yaşayan öğrenci yüzdeleri düşük \% 2; orta $\% 51$; yüksek \%46,9 olarak bulunmuştur. Yazma kalitesi düzeyi açısından $\% 14,3$ düşük, $\% 65,3$ orta, $\% 20,4$ yüksek düzey olarak belirlenmiştir. 
Tablo 2 .

Değişkenlere Göre Kategoriler

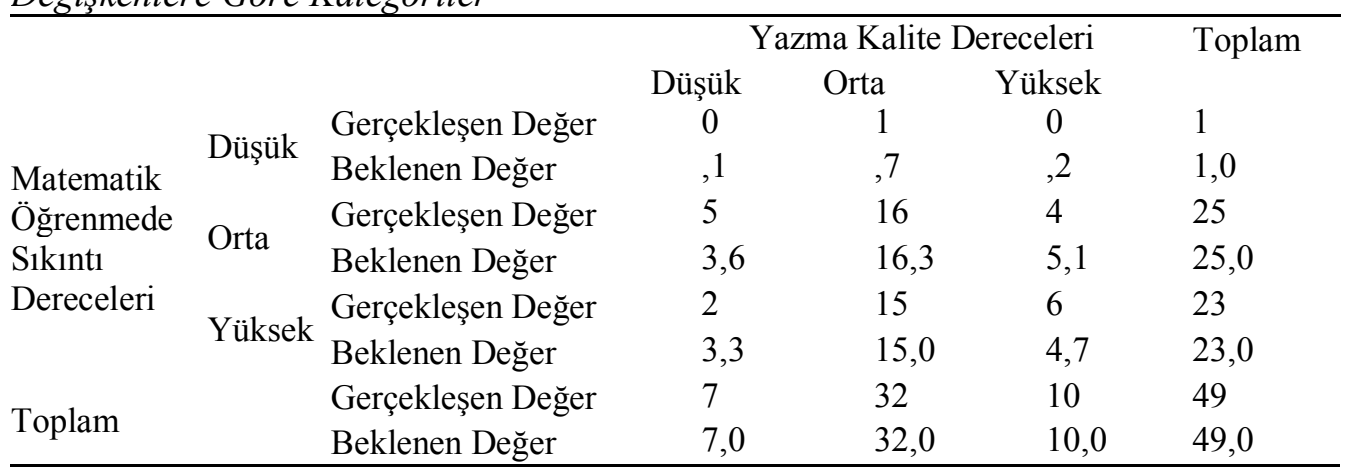

Tablo 2 incelendiğinde nitel değişkenlerin kategorilerinin oluşturduğu 3 x 3 boyutlu ( 9 hücreli) çapraz tablo ve çapraz tablonun her hücresindeki gerçekleşen ve beklenen (teorik) dağılımı göstermektedir. Matematik öğrenmede sıkıntı ve yazma kalitesi bakımından ikisinde birden düşük ve yüksek derecede öğrenci bulunamamıştır.

Tablo 3.

Ki-Kare Değişkenler Arası İlişki Düzeyi

\begin{tabular}{lccccc}
\hline & Değer & df & $\mathrm{p}$ & Exact $\mathrm{p} 2$ & Exact $\mathrm{p} 1$ \\
\hline Pearson ki-kare & $2,214^{\mathrm{a}}$ & 4 &, 696 &, 695 & \\
Fisher's Exact (kesin) Test & 2,800 & & &, 695 & \\
Doğrusal ilișki & $1,423^{\mathrm{b}}$ & 1 &, 233 &, 267 &, 167 \\
\hline
\end{tabular}

a. 6 hücrede $(\% 66,7)$ beklenen değer 5 'den az minimum beklenen sayı 14

Tablo 3 incelendiğinde verilerin analizi ile elde edilen sonuç tablosunda 5'ten küçük hücre sayısının oranı \%66,7 olarak bulunmasından dolayı Fisher's (kesin) exact test kullanılmıştır. Yapılan analize göre exact (kesin) test sonucunda $\mathrm{p}$ değeri 0,695 bulunmuştur. $\mathrm{Bu}$ durum matematik öğrenmede sıkıntı yaşayan öğrenciler yazma kalitesi açısından değerlendirildiğinde bu iki değişken arasında istatiksel anlamda bir ilişki olduğu şeklinde yorumlanabilir. Daha açı ifade edilirse öğrencilerin matematik öğrenmede sıkıntı yaşama düzeyleri arttıkça yazma kalitesi düzeylerinin düştüğü söylenebilecektir.

Tablo 4

Matematik Öğrenme Sıkıntı Düzeyi ile Yazma Kalitesi Düzeyi Arasındaki İlişki Gücünü Gösteren Ki-kare Tablosu

\begin{tabular}{lccc}
\hline & Değer & $\mathrm{p}$ & Exact $\mathrm{p}$. \\
\hline Olumsuzluk Katsayıs1 &, 208 &, 696 &, 698
\end{tabular}

Tablo 4 incelendiğinde matematik öğrenmede sıkıntı yaşama ile yazma kalitesi düzeyleri arasındaki ilişki değeri 0,208 ve X2'nin anlamlılık derecesi $p=0,698$ gerçekleştiği için matematik öğrenmede sıkıntı yaşayan öğrencilerin aynı zamanda yazma kaliteleri arasında bir ilişkinin varlığ söylenebilir. Bu durumda var olan ilişkinin gücünden söz edilmesi uygundur.

Tablo 5

Matematik Öğrenme Sıkıntı Düzeyi ile Yazma Kalitesi Düzeyi Arasındaki IIlişki Düzeyini Gösteren Ki-kare

\begin{tabular}{lcccc}
\hline & Değer & df & $\mathrm{P}^{1}$ & $\mathrm{P}^{2}$ \\
\hline Pearson ki-kare & $2,214^{\mathrm{a}}$ & 4 &, 696 &, $698^{\mathrm{b}}$ \\
Olabilirlik oranı & 2,543 & 4 &, 637 &, $698^{\mathrm{b}}$ \\
Fisher's Exact (kesin) Test & 2,800 & & &, $698^{\mathrm{b}}$ \\
Doğrusal İlişki & $1,423^{\mathrm{c}}$ & 1 &, 233 &, $262^{\mathrm{b}}$ \\
\hline
\end{tabular}


Tablo 5 incelendiğinde matematik öğrenme sıkıntı düzeyi ile yazma kalitesi düzeyi arasındaki ilişkinin gücünü ifade ederken exact testinde p2 değeri 0,698 bulunduğu için doğrusal bir ilişkiden söz edilebilir. $\mathrm{Bu}$ ilişki matematik öğrenmede sıkıntı düzeyi arttıkça yazma kalitesinin de düştüğü biçiminde yorumlanabilir. Matematikte gözlenen sıkıntının aynı zamanda yazma kalitesini etkilediği ya da yazma kalitesi derecesi düştükçe matematikte sıkıntının arttığı söylenebilir.

Tablo 6

Matematik Öğrenmede Sıkıntı Yaşayan Öğrencilerin Yazma Kaliteleri Arasindaki IIlişkinin Büyüklüğ̈̈

\begin{tabular}{llccccc}
\hline & & Değer & sd & Yaklaşık T $^{\mathrm{b}}$ & $\mathrm{P}^{1}$ & $\mathrm{P}^{2}$ \\
\hline Kategorik & Phi &, 213 & & &, 696 &, $693^{\mathrm{c}}$ \\
Siralı & Kendall's tau-b &, 168 &, 126 & 1,320 &, 187 &, $239^{\mathrm{c}}$ \\
\hline
\end{tabular}

Tablo 6 incelendiğinde ilişkinin büyüklüğünü belirleme açısından Kendall’s tau-b -1 ve +1 arasında değer alır. Tam negatif yönlü bir ilişki için -1 değeri; tam pozitif yönlü bir ilișkiden söz edebilmek için +1 değerini alır. Örneklem büyüklüğü açısından örneklem sayısının küçük olduğu durumlarda kullanılmaktadır. Bu çalışmada p2 değeri 0,239 olduğu için pozitif yönlü düşük düzeyde bir iliş̧iden söz edilebilir (Kılıç, 2012). Bu bulgudan hareketle matematik öğrenme sıkıntı düzeyi ile yazma kalite düzeyi arasında var olan ilişkiye dair yorum yapılabilir

\section{Sonuç, Tartışma ve Öneriler}

$\mathrm{Bu}$ çalışmada öğrencilerin matematik öğrenmede sıkıntı yaşama düzeyleri ile yazma kalitesi düzeylerinin benzer olduğu sonucuna ulaşılmıştır. Ayrıca araştırmada elde edilen veriler doğrultusunda matematik öğrenme sıkıntı düzeyi ile yazma kalite düzeyi arasında pozitif yönlü bir ilişki olduğu bulgusuna ulaşılmıştır. Bu çalışmada katılımcılar matematik öğrenme sürecinde sıkıntı yaşamaktadırlar. Yaşadıkları bu sıkıntının aynı zamanda katılımcıların yazma kaliteleri ile etkileştiği görülmüştür. Altay ve Göker'in (2016) çalışmasında özgül öğrenme güçlüğü olan bireylerde en sık karşılaşılan okuma, yazma ve matematik bozukluklarının birlikte olduğu bozukluk oranını \%37,5 olarak ifade etmektedir. Matematik bozukluğu belirlemede kullanılan testlerde elde edilen puanların düşük olduğu ve bu öğrencilerin aynı zamanda okuma yazma becerilerini geç kazandıklarını bu üç bozukluğun birlikte sürdüğünü ifade etmektedir. Jordan ve Hanich'in (2015) çalışmasında matematikte güçlük yaşayan öğrencilerin normal öğrencilere göre daha düşük performans sergiledikleri belirtilmektedir. Bu çalışmada yer alan sonuçlar ilişkilendirildiğinde bize önemli ipuçları vermektedir. Ramaa ve Gowramma'nın (2002) matematik öğrenme güçlüğü çeken öğrencileri belirleme amacıyla yaptığı çalışmasının ikinci bölümünde matematik öğrenme güçlüğü yaşayan 78 öğrenciden 40'ında okuma ve yazma güçlükleri belirlenmiştir. Arıkan ve Ünal'ın (2013) ilköğretim ikinci sınıf öğrencilerinin matematiksel problem kurma becerilerinin incelenmesi adlı çalışmalarında bazı öğrencilerin istenilen şekilde problem kuramadıklarını bunun Türkçe'yi etkin kullanamama ve kavram yanılgılarına düşme ile açıklanabileceği belirtilmektedir. Napoli ve Purpura (2017) çalışmasında erken okuma yazma öğrenme ile matematik becerilerinin gelişimi arasında bir ilişkinin varlığından bahsetmektedir. Layes, Lalonde, Bouakkaz ve Rebai'nın (2017) çalışmasında işleyen bellek kapasitesi geliştirilmesi eğitiminin sonuçları diskalkuli ve disleksi gruplarının her ikisinde de gelişme kaydedildiğine ve bu iki bozukluk arasında güçlü bir ilişkinin varlığına dikkati çekmektedirler. Arslan ve Babadoğan'nın (2005) çalışmasında öğrencilerin soyut düşünme becerileri arttıkça Türkçe dersinde başarılarının arttı̆g 1 bulgusu matematik öğrenmede sıkıntı yaşayan öğrencilerin yazma kalite düzeyleri arasındaki ilişki açısından önemli bir ipucu verdiği söylenebilir.

Matematik ve yazma kalitesi ile doğrudan ilişki kurmadan yapılan çalışmalarda elde edilen bulgulardaki matematik öğrenme becerileri ile dil arasında bir ilişkinin varlığına yönelik ifadelerin yer alması yapılan bu çalışmalarda dolaylı olarak matematik başarısı ile yazma kalitesi arasında bir ilişkinin varlığına işaret etmektedir. Matematik ile yazma kalitesi arasında bulunan bu ilişki düzeyinin belirlenmesi için daha detaylı ve kapsamlı çalışmalar yapılabilir. Daha fazla öğrenci ve öğretmen ile çalışılarak ilişkinin varlığı üzerinde nitel ve nicel araştırmaların gerekli olduğu düşünülmektedir. Yine 
matematik öğrenme ile yazma kalitesi arasındaki ilişkide etkili olan bilişsel, nörolojik ve fizyolojik faktörler hakkında ayrıntılı çalışmalar yapılabileceği düşünülmektedir.

Açıklamalar: Araştırma 17. Uluslararası Sınıf Öğretmenliği Sempozyumu'nda (11-14 Nisan 2018-Ankara) sözlü bildiri olarak sunulmuştur 


\section{Kaynaklar}

Altay, M. A. ve Görker, I. (2016). DSM- 5 kriterlerine göre özgül öğrenme bozukluğu tanısı alan olguların psikiyatrik eştanı ve wısc-r profllerinin değerlendirilmesi. Ulusal Çocuk ve Ergen Psikiyatrisi Kongresi'nde sunulmuştur. İzmir: Türk Nöropsikiyatri Derneği. www.noropskiyatriarsivi.com adresinden erişilmiştir.

Arıkan, E. E. ve Ünal, H. (2013). İlköğretim 2. snıf öğrencilerinin matematiksel problem kurma becerilerinin incelenmesi. Amasya Üniversitesi Ĕ̈itim Fakültesi Dergisi, 305325.

Arslan, B. ve Babadoğan, C. (2005). İlköğretim 7. ve 8. sınıf öğrencilerinin öğrenme stillerinin akademik başarı düzeyi, cinsiyet ve yaş ile ilişkisi . Eurasian Journal of Educational Research, 21, 35-48.

Baroody, J. ve Kaufman, L. (1993). The case of lee: Assessing and remedying a numeralwriting difficulty. doi:https://doi.org/10.1177/004005999302500304

Bender, W. N. (2016). Learning Disabilities. (H. Sarı, Çev.) Ankara: Nobel Akademik Yayıncılık Eğitim Danışmanlık Tic. Ltd. Şti.

Borasi, R. ve Rose, B. J. (1989). Journal writing and mathematics instruction. Educational Studies in Mathematics, 20(4), 347-365.

Burns, M. (2005). Building a teaching bridge from reading to math. Leadership Compass, 3(2), 1-2.

Büyüköztürk, Ş., Çokluk, Ö. ve Köklü, N. (2016). Sosyal bilimler için istatistik. Ankara: Pegem Akademi.

Çepni, S. (2012). Araştırma ve proje çalışmalarına giriş. Trabzon: Celepler Matbaa.

Crossley, S. ve McNamara, D. (2016). Say more and be more coherent: How text eleboration and cohesion can increase writing quality. Journal of Writing Research, 7(3), 351370 .

Emerson, J. ve Babtie, P. (2010). The dyscalculia assessment. London: Continuum International Publishing Group.

Garnett, K. (1992). Developing Fluency with Basic Number Facts: Intervention for Students with Learning Disabilities. Learning Disabilities Research ve Practice. 24.11.2017 tarihinde

http://www.cusdmathcoach.com/developing_fluency_with_basic_number_facts.pdf adresinden erişilmiştir.

Geary, D. C., Hoard, M. K., Byrd-Craven, J. ve Desoto, M. C. (2004). Strategy choices in simple and complex addition: Contributions of working memory and counting knowledge for children with mathematical disability. Journal of Experimental Child Psychology, 88(2), 121-151.

Görker, I., Bozatlı, L., Korkmazlar, Ü., Karadağ, M. Y., Ceylan, C., Sögüt, C., . . . Turan, N. (2017). The probable prevalence and sociodemographic characteristics of specifc learning disorder in primary school children in Edirne. Arch Neuropsychiatr. 11. 20. 2017 tarihinde www.noropskiyatriarsivi.com adresinden erişilmiştir.

Gross-Tsur, V., Manor, O. ve Shalev, R. S. (1996). Developmental dyscalculia prevalence and demographic features. Developmental Medicine ve Child Neurology, 25-33.

Jasper, I., Gordijn, M., Häußler, A. ve Hermsdörfer, J. (2011). Circadian rhythms in handwriting kinematics and legibility. Human Movement Science (30), 818-829.

Johnson, M. L. (1983) "Writing in mathematics classes: A valuable tool for learning." The Mathematics Teacher 76(2), 117-119.

Jordan, N. C., ve Hanich, L. B. (2015). Mathematical thinking in second grade children with different forms of LD. Journal Of Learning Disabilities, 567- 578. 
Kalaç, E. T. (2017). Öğrenme güçlüğü ve matematik. İçinde Melekoğlu, M. A. ve Çankıroğlu, O. (Ed.), Özel Öğrenme Güçlüğ̈̈ Olan Çocuklar (245-276). Ankara: Vize Yayıncilik.

Karagiannakis, G. N. ve Baccaglini-Frank, A. E. (2014). The Dedima battery: A tool for identifying students' mathematical learning profiles. Health Psychology Report Volume 2(4). doi:10.5114/hpr.2014.46329.

Karasar, N. (2006). Bilimsel arastırma yöntemi. 16. Baskı Ankara: Nobel Yayıncılık

Kılıç, S. (2012). Bağıntı analizi sonuçlarının yorumlanması. Journal of Mood Disorders, 2(4), 191-3.

Layes, S., Lalonde, R., Bouakkaz, Y. ve Rebai, M. (2017). Marta Olivetti Belardinelli and Springer-Verlag GmbH Germany, part of Springer Nature. doi:https://doi.org/10.1007/s10339-017-0853-2.

Lindgren, E. (2005). Writing and revision. Didactic and methodological implications of keystroke logging. Institutionen för Moderna Språk. Umea Universitet.

MEB-TTKB (2018). Matematik dersi öğretim programı (İlkokul ve Ortaokul 1, 2, 3, 4, 5, 6, 7 ve 8. Sinıflar). Ankara: MEB Talim ve Terbiye Kurulu Başkanlığı.

Miller, L. D. (1991). Writing to learn mathematics. The mathematics teacher, 84(7), 516-521.

Moyer, Patricia S. (2000). Communicating mathematically: Children's literature as a natural connection." The Reading Teacher. 54(3), 246-255.

Mutlu, Y. (2016). Matematik öğrenme güçlügü (gelişimsel diskalkuli). Matematik eğitiminde teoriler. Pegem Akademi. 26.11.2017 tarihinde https://www.researchgate.net/profile/Yilmaz_Mutlu/publication/318130080_Matema tik_Ogrenme_Guclugu_Gelisimsel_Diskalkuli/links/595b7898a6fdcc36b4dc27c8/M atematik-Oegrenme-Guecluegue-Ge-lisimsel-Diskalkuli.pdf adresinden erişilmiştir.

Mutlu, Y. ve Akgün, L. (2017). Matematik öğrenme güçlüğünü tanılamada yeni bir model önerisi: Çoklu süzgeç modeli. Elementary Education Online, 1153-1173. doi: http://ilkogretim-online.org.tr.

Napoli, A. R. ve Purpura, D. J. (2017). The home literacy and numeracy environment in preschool: Cross-domain relations of parent-child practices and child outcomes. Journal of Experimental Child Psychology 166(2018), 581-603. doi:https://doi.org/10.1016/j.jecp.2017.10.002.

Olinghouse, N. G. ve Wilson, J. (2013). The relationship between vocabulary and writing quality in three genres. Read Write (26), 45-65.

Olive, T. (2003, December). Working memory in writing: emprical evidence form the dualtask technique. European Psychologist, 1-10.

Özmen, R. G. (2017). Öğrenme güçlüğü olan öğrenciler. Diken, İ. H. İçinde (Ed), Özel Ĕ̆gitim (369-401). Ankara: Pegem Akademi.

Petra Scherer, K. B. (2017). Assistance of students with mathematical learning difficultiesHow can research support practice?-A Summary. Proceedings of the 13th International Congress on Mathematical Education, ICME-13 Monographs DOI 10.1007/978-3-319-62597-3_16, 249-259.

Ramaa, S. ve Gowramma, I. P. (2002). A systematic procedure for identifying and classifying children with dyscalculia among primary school children in India. Dyslexia, 8(2), 67-85.

Riccomini, P. J. (2005). Identification and remediation of systematic error patterns in subtraction. 233-242. doi:https://doi.org/10.2307/1593661

Robinson, C. S., Menchetti, B. M. ve Torgesen, J. K. (2002). Toward a two-factor theory of one type of mathematics disabilities. Learning Disabilities Research ve Practice, 8189. 
Shalev, R. ve Gross-Tsur, V. (2001). Developmental dyscalculia. Pediatr Neurol, May; 24(5):337-42. Review. PubMed PMID: 11516606.

Sousa, D. A. (2014). How the brain learns mathematics. Corwin Press.

Sullivan, M. M. (2005). Teaching mathematics to college students with mathematics-related learning disabilities: Report from the classroom. Learning Disability Quarterly. 26.11.2017 tarihinde https://files.eric.ed.gov/fulltext/EJ725673.pdf adresinden erişilmiştir.

Terry, W. S. (2013). Öğrenme ve bellek, temel ilkeler, süreçler ve işlemler. (B. Cangöz, Çev.) Ankara: Anı Yayıncilık.

Toptaş, V. ve Gözel, E. (2018). Türkiye'de matematik kaygısı ile ilgili yapılan lisansüstü tezlerin içerik analizi. Eğitim Kuram ve Uygulama Araştırmaları Dergisi. 4(3).136146.

Ülper, H. (2008). Bilişsel süreç modeline göre hazırlanan yazma öğretim programının öğrenci başarisina etkisi. Doktora tezi. Ankara Üniversitesi, Sosyal Bilimler Enstitüsü Dilbilim (Türkçenin Eğitimi ve Öğretimi) Anabilim Dalı, Ankara.

Vanderburg, R. (2005). Working memory contributions to analytical and creative writing samples in high school students. (UMI Number3179407). University of California Riverside.

Vukovich, D. (1985). Ideas in practice: Integrating math and writing through the math Journal. Journal of Developmental Education, 9(1), 19-20.

Watson, S. ve Gable, R. (2012). Unraveling the complex nature of mathematics learning disability: Implications for research and practice. Learning Disability Quarterly, 36(3), 178-187.

White, M. J. ve Bruning, R. (2005). Implicit writing beliefs and their relation to writing quality. Contemporary Educational Psychology, 30, 166-189.

Williamson, M. M. ve Mcandrew, D. A. (1987, January). Writing in college developmental mathematics. Research and Teaching in Developmental Education, 3(1), 14-21.

Wilmshurt, L. ve Brue, A. W. (2010). The Complete Guide to Special Education. 989 Market Street, San Francisco. 


\section{Extended Abstract}

\section{Introduction}

Learning disability can be described as the inefficacy appearing in a skill at a certain level in a certain domain without affecting other domains. The students experiencing learning disability also have social and emotional difficulties (Terry, 2013). Deficiency in language, perception, attention, memory, recollection, coding and recall, and features such as noticing details less can be observed in the students who have learning disabilities (Bender, 2016). In the students who do not have learning disability, learning difficulties in various fields of mathematics can arise in spite of normal intelligence, adequate education and teaching activities (Mutlu and Akgün, 2017). Some students might show inefficacy in either reading or mathematics domain, some might show inefficacy in both domains (Robinson, Menchetti and Torgesen, 2002). Theoretically, a majority of the educators concur on the fact that all teachers are also reading-writing teachers. An increasing number of studies claim that reading and writing skills are important elements creating a unity in all learning domains and that interdisciplinary approach in learning is beneficial. Additionally, a lot of teachers have difficulty in transforming this theory into the practice since some subjects of mathematics are less related to reading and writing (Vukovich, 1985).

From this point, the aim of the study is to determine whether there is a relationship between the difficulties experienced in mathematics learning and writing quality level of the students who are not diagnosed as having learning disability but academically cannot have adequate success in mathematics courses within classroom.

\section{Method}

The research is in correlational survey model from general survey models. It has been searched whether there is a relationship between the students' levels of experiencing difficulty in mathematics learning and writing quality levels and the degree of this relationship. The study group of the research was determined by criterion sampling from purposeful sampling methods. 49 students studying at 5 elementary schools in Kutahya city center and in a district created the study group. The necessary permissions were provided from the schools included in the research. The detailed face-toface interviews were done about the research subject, the structure of behavior checklist and how they will fill in the list with the teachers. The data of the research were collected via Mathematics Learning Difficulty Behavior Checklist and Writing Quality Scoring Rubric, which were prepared by the researchers. Mathematics Learning Difficulty Behavior Checklist was filled on the basis of voluntariness principle by 24 elementary teachers who teach at 4th grade and whose classrooms include at least one student considered to have difficulty in learning mathematics. A total of 49 students whom 24 elementary teachers determined and who were considered to have difficulty in mathematics learning were asked to write a story which would be their own creations in convenient circumstances. The obtained 49 texts were evaluated through "Writing Quality Scoring Rubric" and the data for writing quality were collected. Firstly, percentage (\%) and frequency (f) values were calculated when the teacher opinions about the expressions in checklist were analyzed. A classification of mathematics learning difficulty was obtained by utilizing the rank done in terms of the repeat number. According to this classification, difficulties were categorized by 33-23 high level, 22-12 medium level and 1-11 low level of difficulty. In the data obtained via Writing Quality Scoring Rubric, the students were collected under three categories as low, medium and high level. The three categories were determined as 0-10 high level of difficulty, 11-20 medium level of difficulty and 2130 low level of difficulty. The relationships between variables were analyzed via chi-square test. Chisquare test, which is a non-parametrical one, is used for testing whether the values observed in the pores emerging in terms of the levels of dual classified variable differ significantly from the expected value. The significance probability of the relationship between variables increases as much as the difference between two variables increases (Büyüköztürk, Çokluk, ve Köklü, 2016). 


\section{Findings, Discussion and Results}

It has been concluded in this study that the students' level of experincing difficulty in mathematics learning is similar to their writing quality. Additionally, it has been found that there is a positive relationship between mathematics learning difficulty level and writing quality level in accordance with the data obtained in the research. In this study, the participants experience difficulty in mathematics learning process. In Altay and Goker's (2016) study, it is stated that the rate of disorder including most frequent reading, writing and mathematics disorders together is $37,5 \%$ in the individuals who have specific learning disability. In the second part of Ramaa and Growramma's study purposing to determine the students who have mathematics learning difficulty, it is identified that 40 students out of 78 students who have mathematics learning difficulty have reading and writing difficulties. In Arıkan and Unal's study titled as investigation of second grade elementary students' mathematical problem posing skills, it is stated that some students cannot pose problems in the required way and this can be explained with their ineffective use of Turkish and misconception. Napoli and Purpura (2017) point out the existence of a relationship between early learning of readingwriting and development of mathematical skills in their studies. In Layes, Lalonde, Bouakkaz and In Arslan and Babadoğan's (2005) study, it can be said that the finding that concrete thinking skills increase in parallel with their Turkish course achievement gives an important clue in terms of the relationship between the levels of students' difficulty experience in mathematics learning and their writing quality.

The findings in the studies which do not directly establish a relationship between mathematics and writing quality include some certain expressions about the existence of a relationship between mathematics learning skills and language and this indirectly indicates a relationship between mathematical achievement and writing quality in these studies. It is considered that both qualitative and quantitative researches about the relationship are necessary by studying with more students and teachers. Once again, it is considered that detailed studies about cognitive, neurological and physiological factors affecting the relationship between mathematics learning and writing quality. 